\title{
Designing an Intelligent System for Traffic Management
}

\author{
Maha Rezzai ${ }^{1}$, Wafaa Dachry ${ }^{2}$, Fouad Moutaouakkil ${ }^{1}$, and Hicham Medromi ${ }^{1}$ \\ 1. Systems Architecture Team, Laboratory of Computer System and Renewable Energy, University Hassan II Casablanca ENSEM \\ Casablanca 20200, Morocco
}

2. Laboratory of Mechanical Engineering, Industrial Management and Innovation (IMMII) University Hassan I, FST Settat, Morocco

\begin{abstract}
Traffic congestion has become a serious problem that arises in our cities; this is due to rapid population growth, the rapid increase in the number of cars. Therefore, there is an infernal traffic jams. It is in this light, it is imperative to eliminate or at least reduce traffic congestion through the adoption of the policy of ITS (intelligent transport systems). The objective of this paper is to propose a study on the problem of congestion in cities, by reducing traffic congestion.
\end{abstract}

Key words: Intelligent transportation systems, multi agent systems, reinforcement learning, traffic signal control, Q-learning.

\section{Introduction}

Casablanca suffers from traffic congestion. This is due to several factors, such as rapid population growth, poor road infrastructure, rapid increase in number of cars, social and economic activities in the city. Morocco's economic city has already implemented many strategies to minimize traffic congestion which we quote: the construction of tram lines, new underpasses at key intersections of roads and improvement of public transport. However, these strategies cannot fully overcome congestion in Casablanca, especially in the peak hours, where people want to move as fast as possible, in an efficient and sustainable manner. Therefore we find infernal traffic jams. We are talking about congestion where citizen's demand exceeds road capacity. This is an undesirable event, because it has several harmful effects [1], which we quote:

- Increased congestion increases the travel time;

- Increased congestion reduces the security level of the vehicles and pedestrians [2];

- Increased congestion increases fuel consumption,

Corresponding author: Maha REZZAI, Ph.D., research field: intelligent transportation systems. E-mail: maha.rezzai@gmail.com. which has an adverse economic impact [1].

In this context it is imperative to eliminate or at least reduce traffic congestion. Therefore, the most appropriate solution to the traffic congestion problem is to adopt the policy of intelligent transportation systems. ITS (intelligent transportation systems) are applications or services combining advanced technologies of ICT (information and communication technologies) to transport engineering [3]. ITS is a real issue of the common transport policy and are considered a useful tool to improve the performance of road infrastructure in terms of safety, traffic flow, and reduce $\mathrm{CO} 2$ emissions [4].

The figure below illustrates the goals of ITS policy:

The main objectives are [5]: Optimizing the use of existing capacities of the different modes; Improving road safety through understanding the rules to be applied, improving the quality of life in cities, by facilitating the use of public transport, including multimodal information and ticketing, reducing inequalities through action on accessibility, and controlling energy consumption and emissions of gases, by reducing congestion.

The objective of this paper is to propose a study concerning the problem of congestion in the city of Casablanca, to improve the quality of transport in 


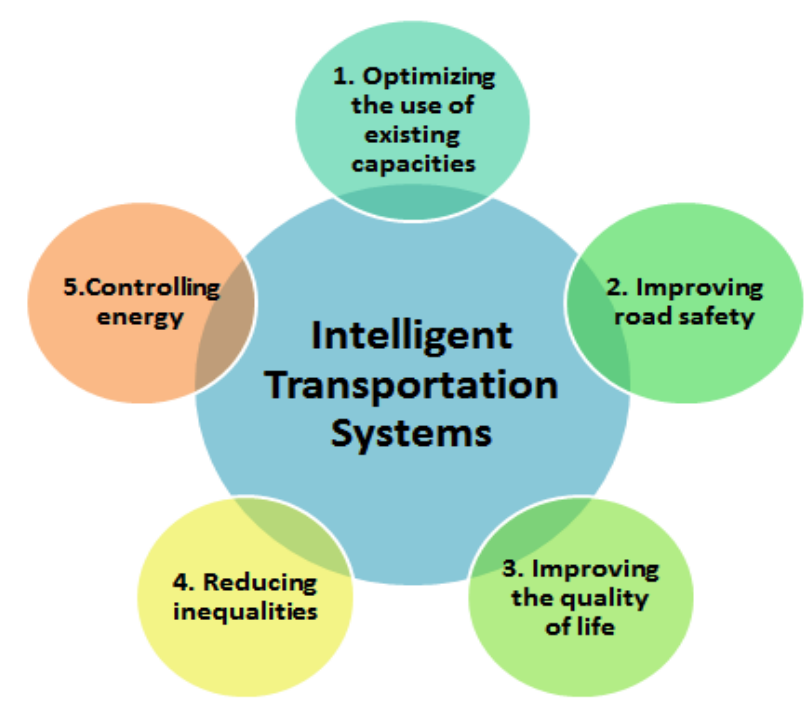

Fig. 1 Main objectives of ITS.

terms of reducing traffic congestion. In other words, minimize waiting time at intersections allowing automatic reduction of accidents and emergencies.

The paper is organized as follows: Section 2 examines the control systems of existing traffic lights in the literature; Section 3 introduces the fundamentals of multi-agent architecture; Section 4 shows the basic principles of reinforcement learning; Section 5 defines the problem; Section 6 is the conclusion.

\section{State of the Art}

Traffic signals controller has been studied by many researchers, intended to reduce traffic congestion at intersections, we quote: Robertson and Bretherton [6] propose a method SCOOT, for optimizing traffic signal networks in real time, by reducing the average queue length. In addition, Miakami and Kakazu [7] propose a method allowing cooperation between traffic lights. The idea is this: Each agent performs reinforcement learning RL and reports; its evaluation combinatorial optimization is carried out simultaneously, to find the appropriate settings for the long-term learning that maximize the total profit of the signals. Thorpe [8] applied RL called SARSA to control traffic lights SARSA minimizes the total time traffic travel, individual vehicle travel time to four lanes and waiting time of vehicles. While Porch and
Lafortune [9] propose a decentralized traffic control system in real time named ALLONS-D. The purpose of the latter is to optimize the traffic lights, in order to minimize delays and waiting times. The ALLONS-D requires the use of a signal optimizer in each intersection, claiming the information on the current queue length and future arrivals. Whereas Bingham [10] proposes rules on the basis of fuzzy logic, that allocates time of green based on the number of vehicles. The purpose of learning is to minimize the delay caused by vehicles of the signal control policy. And Ferreira et al. [11] propose a decentralized multi-agent strategy to control urban traffic network. Each agent is responsible for managing the signals of an intersection, through evaluation and current traffic queue lengths. In addition, Abdulhai et al. [12] apply the Q-learning algorithm to optimize control signal of a single intersection. The objective involves optimal traffic control severely disrupted, through a road network in two dimensions. Whereas Oliveira and Bazzan [13] propose an intersection control approach, based on agents who engage in coordination protocol, to collectively decide the direction of flow that should be prioritized. While Arel et al. [14] introduced a reinforcement learning RL system multi-agent to obtain a control policy for efficient traffic lights, to minimize the average delay, congestion and probability of blocking in an intersection. Abdul Aziz et al. [15] propose a technique called RMART, controlling the signal lights using the Markov decision process in a multi-agent framework. And finally, Samah et al. [16] propose a system called ATSC-MARLIN, where agents manage to coordinate and cooperate. In other words, the lights no longer obey timers or only visual sensibilities. Table 1 summarizes the different design programs for the control of traffic signal.

\section{Multi Agent Approach}

The multi-agent systems [17] are a set of agents who have some autonomy, a degree of intelligence, a 


\begin{tabular}{|c|c|c|c|c|c|c|}
\hline Method & Year & $\begin{array}{l}\text { Objective for } \\
\text { optimization }\end{array}$ & $\begin{array}{l}\text { Methodologies } \\
\text { adopted }\end{array}$ & $\begin{array}{l}\text { Origin } \\
\text { country }\end{array}$ & Result & $\begin{array}{l}\text { Servo } \\
\text { mechanism }\end{array}$ \\
\hline SCOOT & 1981 & $\begin{array}{l}\text { Traffic lights } \\
\text { optimization network }\end{array}$ & $\begin{array}{l}\text { Observation of the } \\
\text { queue length }\end{array}$ & UK & $\begin{array}{l}\text { Reduce the queue } \\
\text { length }\end{array}$ & Centralized \\
\hline $\begin{array}{l}\text { Genetic reinforcement } \\
\text { learning for cooperative } \\
\text { traffic signal control }\end{array}$ & 1994 & $\begin{array}{l}\text { Cooperation between } \\
\text { traffic lights }\end{array}$ & $\begin{array}{l}\text { Each agent performs } \\
\text { reinforcement learning }\end{array}$ & JAPAN & $\begin{array}{l}\text { Maximize the total } \\
\text { profit of the signals }\end{array}$ & Decentralized \\
\hline SARSA & 1997 & Control traffic lights & $\begin{array}{l}\text { Markov decision } \\
\text { process }\end{array}$ & Canada & $\begin{array}{l}\text { Minimize of the time } \\
\text { in the queue }\end{array}$ & Decentralized \\
\hline ALLONS-D & 1998 & $\begin{array}{l}\text { Traffic control system in } \\
\text { real time }\end{array}$ & $\begin{array}{l}\text { Using signal optimizer } \\
\text { in each intersection }\end{array}$ & USA & $\begin{array}{l}\text { Minimize delays and } \\
\text { waiting times }\end{array}$ & Decentralized \\
\hline $\begin{array}{l}\text { Intelligent agents in } \\
\text { decentralized traffic } \\
\text { control }\end{array}$ & 2001 & $\begin{array}{l}\text { Urban traffic network } \\
\text { control }\end{array}$ & Multi agent systems & Uruguay & $\begin{array}{l}\text { Managing the signals } \\
\text { of an intersection } \\
\text { through evaluation }\end{array}$ & Decentralized \\
\hline $\begin{array}{l}\text { Reinforcement learning } \\
\text { for true adaptive traffic } \\
\text { signal control }\end{array}$ & 2003 & $\begin{array}{l}\text { Optimal control of } \\
\text { disrupted traffic }\end{array}$ & Q-learning & Canada & $\begin{array}{l}\text { Optimization of an } \\
\text { isolated intersection } \\
\text { signal }\end{array}$ & Decentralized \\
\hline $\begin{array}{l}\text { Using cooperative } \\
\text { mediation to coordinate } \\
\text { traffic lights }\end{array}$ & 2005 & $\begin{array}{l}\text { Priority directions of } \\
\text { traffic }\end{array}$ & Multi agent systems & Portugal & Coordination protocol & Decentralized \\
\hline $\begin{array}{l}\text { Reinforcement } \\
\text { learning-based } \\
\text { multi-agent system for } \\
\text { network traffic signal } \\
\text { control }\end{array}$ & 2010 & $\begin{array}{l}\text { Efficient control of } \\
\text { traffic lights }\end{array}$ & $\begin{array}{l}\text { Reinforcement } \\
\text { learning } \\
\text { Multi agent systems }\end{array}$ & USA & $\begin{array}{l}\text { Minimize the average } \\
\text { delay Probability of } \\
\text { blocking }\end{array}$ & Decentralized \\
\hline RMART & 2013 & $\begin{array}{l}\text { Controlling the signal } \\
\text { lights }\end{array}$ & $\begin{array}{l}\text { Markov decision } \\
\text { process } \\
\text { Multi-agent systems } \\
\end{array}$ & USA & $\begin{array}{l}\text { Reduce the queue } \\
\text { length }\end{array}$ & Decentralized \\
\hline MARLIN-ATSC & 2013 & $\begin{array}{l}\text { Coordination and } \\
\text { cooperation between } \\
\text { signal }\end{array}$ & $\begin{array}{l}\text { Q-learning } \\
\text { Multi agent systems }\end{array}$ & Canada & $\begin{array}{l}\text { The lights no longer } \\
\text { obey timers }\end{array}$ & Decentralized \\
\hline
\end{tabular}

representation of their environment with whom they interact. Also, they are able to take the initiative, communicate with each other and adapt to different situations [18].

\subsection{Paradigm Agent}

An agent is defined as an intelligent entity independently, able to communicate with other agents, to perceive and to represent its environment. Each agent performs specific actions based on their perception of its environment. A set of interacting agents form a multi-agent systems.

Ferber [19] defines an agent as a physical or virtual entity which is capable of acting in an environment, can communicate directly with other agents, has the own resources, is able to perceive its environment, and provides services.

We can therefore define a MAS (multi-agent system) as a system composed of a set of agents situated in an environment and interacting with each other to achieve a common goal. We distinguish in our model, two types of agents: In the following, we propose to use reinforcement learning considered as an automatic construction method of the agents [20]. Therefore the agent adapts individually its local behavior to treat a global task with decentralized manner.

\section{The Basics of Reinforcement Learning RL}

The reinforcement learning RL [21] as its name suggests, is to learn from experiences what to do in different situations (called policy) based on the success or failure observed (reinforcements or rewards) to optimize quantitative rewards over time.

The RL takes a few simple key concepts based on the fact that the intelligent agent:

- Observes the effects of its actions;

- Inferred from his observations the quality of his actions;

- Improves future actions. 
In reinforcement learning $\mathrm{RL}$ [21], the learning agent interacts firstly with an unknown environment and modifies its action policies to maximize its cumulative gains. Thus, RL provides an effective framework for solving control learning problems that are difficult or even impossible.

Indeed, the RL can be modeled as a MDP (Markov decision process).

The MDP is defined by a set of states, a set of actions A (s) when I am in state, and reward function $\mathrm{R}$ (s) that informs about the usefulness of being in state; Indeed, the "intelligent" agent decides to perform an action based on its status to interact with its environment. Environment refers reinforcement in the form of a positive or negative reward. The reward here corresponds to the criterion to be optimized in the feedback loop in the theory of optimal control. It is through this loop that improves agent [12].

The figure below illustrates the different existing interactions between the agent and the environment.

In our approach, we will opt for reinforcement learning in order that agents can automatically make decisions by observing their environment.

\section{Problem's Definition}

In this paper we focus on the case of an isolated intersection. Therefore the environment is stationary, it may be considered to be a MDP. Indeed, the objective is to design an intelligent traffic control system that is able to estimate the density of traffic using vehicle density detection sensors, and through the control of traffic signals based on delay. In addition, the traffic signal controller will be considered as an agent. Its objective is collecting data and then, control access through the observation of the queue length to avoid plug or clutter. The road traffic will be considered as the environment. The states are the queue lengths. Thus, the time of the red or green phase, or the transition from red to green, and vice versa will be defined as the different actions performed by the agent. And the reward function is the queue length. Therefore, the traffic signal control problem has all the elements of the MDP.

Furthermore, our system consists of two layers: environment's perception and traffic management.

Regarding the layer environment's perception, it contains all the elements necessary to collect the data, i.e., the input of our system. Therefore, the purpose of this layer is the collect the maximum information about emergency management (traffic accidents, theft, siren, etc.) and the traffic, through observation of the queue length via sensors that detect the density of the congestion. As for, the layer traffic management, it is responsible for decisions and actions through what has been collected since the previous layer. Indeed, the role of the traffic controller agent is regulating congestion, by the estimated time for the red or green phase or the transition from red to green and vice versa.

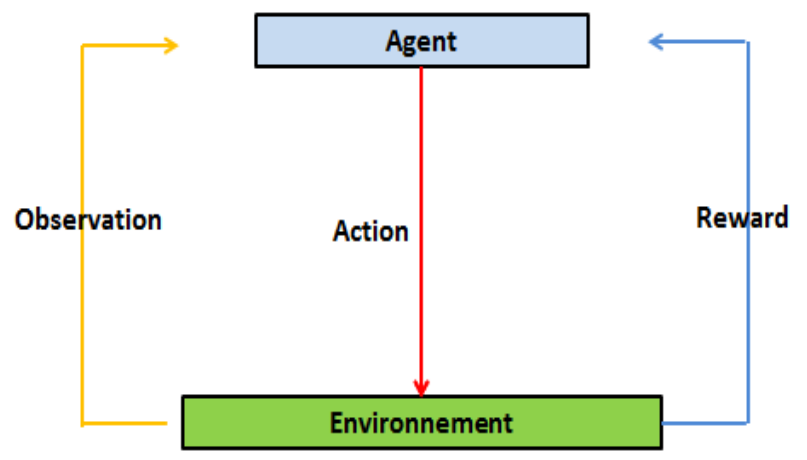

Fig. 2 Interactions between agent and environment.
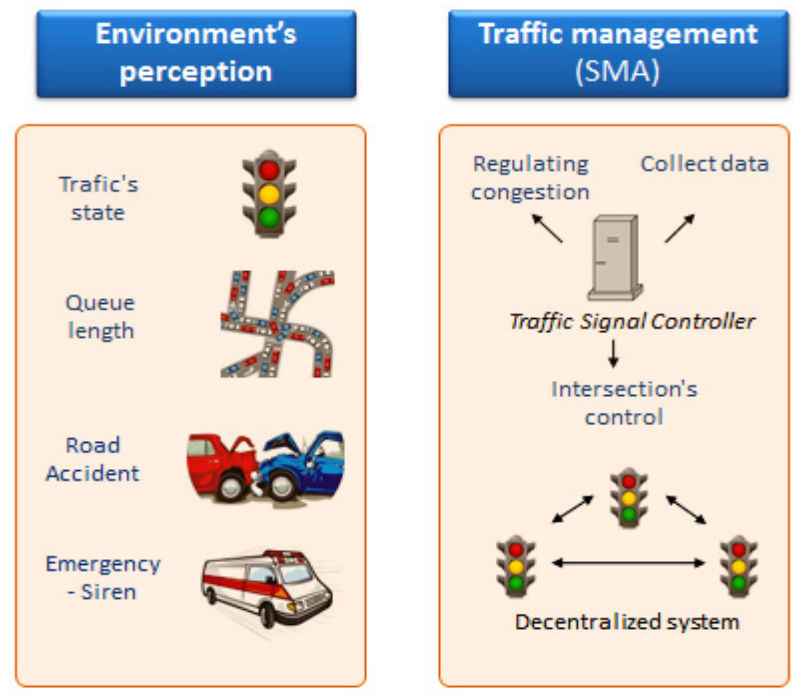

Fig. 3 Different layers of our system. 
For this, the agent must learn to cooperate and coordinate fires, through a decentralized system and make decisions without human intervention through reinforcement learning.

\section{Conclusion}

The purpose of this article is to reduce traffic congestion, even in the most critical hours, and in fact, participated in reducing journey times on the perimeter of the studied area. The proposed approach can be realized on the ground. We will later consider the environment as the mapping of the city of Casablanca. The information must include the traffic arriving the next 10 seconds for each link of traffic. The detected information is expected to become available at the beginning of each time interval.

\section{References}

[1] Shah, N., Kumar, S., Bastani, F., and Yen, I. L. 2012. "Optimization Models for Assessing the Peak Capacity Utilization of Intelligent Transportation Systems." European Journal of Operational Research: 239-51.

[2] Dimitrakopoulos, G., and Demestichas, P. 2010. "Intelligent Transportation Systems." IEEE Vehicular Technology Magazine 5: 77-84.

[3] Rezzai, M., Dachry, W., Moutaouakkil, F., and Medromi, H. 2014. "Ville Intelligente: Un Nouveau Paradigme." Communication aux Journees Doctorales JDTIC.

[4] Serrat, S., Lafont, R., Rostagnat, M., Chavanon, A. M., Dubertret, F., Litchman, A., Leblond, R. 2010. LES SYSTEMES DE TRANSPORTS INTELLIGENTS POUR LA SECURITE ET LA MOBILITE DURABLE SUR LES RESEAUX ROUTIERS.

[5] Ygnace, J. L., de Banville E. 1999. Les systemes de transport intelligent: Un enjeu strategique mondial. Paris: Documentation Francaise.

[6] Hunt, P. B., Robertson, D. I., Bretherton, R. D., and Winton, R. I. 1981. "SCOOT-A Traffic Responsive Method of Coordinating Signals.” Transp. Road Res.

[7] Mikami, S., and Kakazu, Y. 1994. "Genetic Reinforcement Learning for Cooperative Traffic Signal Control." In Proceedings of the First IEEE Conference on Evolutionary Computation, 223-28.

[8] Thorpe, T. 1997. "Vehicle Traffic Light Control Using Sarsa ." Ph.D. thesis, Comput. Sci. Colo.St.
[9] Porche, I., and Lafortune, S. 1998. "Coordination of Local Adaptive Traffic Signal Controllers.” 1833-37.

[10] Bingham, E. 2001. "Reinforcement Learning in Neuro Fuzzy Traffic Signal Control." European Journal of Operational Research 131: 232-41.

[11] Ferreira, E. D., Subrahmanian, E., and Manstetten, D. 2001. "Intelligent Agents in Decentralized Traffic Control. Intelligent Transportation Systems." Proceedings: 705-9.

[12] Abdulhai, B., Pringle, R., and Karakoulas, G. J. 2003. "Reinforcement Learning for True Adaptive Traffic Signal Control." Journal of Transportation Engineering 129: $278-85$.

[13] De Oliveira, D., Bazzan, A. L., and Lesser, V. 2005. "Using Cooperative Mediation to Coordinate Traffic Lights: A Case Study." In Proceedings of the Fourth International Joint Conference on Autonomous Agents and Multiagent Systems, 463-70.

[14] Arel, I., Liu, C., Urbanik, T., and Kohls, A. G. 2010. "Reinforcement Learning-Based Multi-agent System for Network Traffic Signal Control." IET Intelligent Transport Systems 4: 128-35.

[15] Aziz, H., Zhu, F., and Ukkusuri, S. V. 2013. "Reinforcement Learning Based Signal Control Using R-Markov Average Reward Technique (RMART) Accounting for Neighborhood Congestion Information Sharing." In Proceedings of 92nd Transportation Research Board Meeting.

[16] Tantawy, E. S., Abdulhai, B., and Abdelgawad, H. 2013. "Multiagent Reinforcement Learning for Integrated Network of Adaptive Traffic Signal Controllers (MARLIN-ATSC): Methodology and Large-Scale Application on Downtown Toronto." IEEE Transactions on Intelligent Transportation Systems 14: 1140-50.

[17] Dachry, W., Aghezzaf, B., Bensassi, B., Medromi, H., and Sayouti, A. 2011. "Architecture of the Collaborative Information System Based on Multi-agent Systems." SIL.

[18] Ferber, J. 1998. Multi-agent Systems: An Introduction to Distributed Artificial Intelligence. Harlow: Addison-Wesley.

[19] Dutech, A. R., and Charpillet, A. F. 2006. Apprentissage par Renforcement et Theorie des Jeux pour la coordination de Systèmes Multi-Agents. Colloque Africain sur la Recherche en Informatique-CARI .

[20] Mitchell, T. M. 1997. Machine Learning. New York: McGraw-Hill.

[21] Xu, X., Zuo, L., and Huang, Z. 2014. "Reinforcement Learning Algorithms with Function Approximation: Recent Advances and Applications." Information Sciences 261: 1-31. 